\title{
Solidification of Aluminium Alloys Under Ultrasonication: An Overview
}

\author{
H. R. Kotadia ${ }^{1}$ M. Qian $^{2} \cdot$ A. $\operatorname{Das}^{3}$ (I)
}

Received: 14 July 2018/Accepted: 18 September 2018/Published online: 3 October 2018

(C) The Author(s) 2018

\begin{abstract}
An overview of our investigations on solidification microstructure formation under ultrasonication in various $\mathrm{Al}$ alloys and comparison against unrefined or chemically modified microstructures under identical cooling conditions is presented. Primary $\alpha$-Al grains show significant refinement under ultrasonication, even better than established chemical inoculation, in the small ingots investigated. Increased solute content appears to promote grain refining efficiency under ultrasonication. Regular lamellar eutectic in $\mathrm{Al}-33 \mathrm{wt} \% \mathrm{Cu}$ was observed to degenerate into rounded particle morphology and the irregular eutectic of long Si plates in $\mathrm{Al}-11 \mathrm{wt} \% \mathrm{Si}$ were spheroidised into compact form near the ultrasound radiator. Grain refinement under ultrasonication appears to originate from enhanced heterogeneous nucleation under cavitation showing distinct reduction in nucleation undercooling. Eutectic modification, on the other hand, appears to originate from coarsening as the strong fluid flow created under cavitation disturbs the thin diffusion boundary layer ahead of the eutectic growth front.
\end{abstract}

Keywords Ultrasound C Cavitation - Solidification · Grain refinement $\cdot$ Microstructure $\cdot \mathrm{Al}$ alloys

\section{A. Das}

A.Das@swansea.ac.uk

1 Warwick Manufacturing Group, University of Warwick, Coventry CV4 7AL, UK

2 Centre for Additive Manufacturing, School of Engineering, RMIT University, Melbourne, Australia

3 College of Engineering, Swansea University, Bay Campus, Swansea SA1 8EN, UK

\section{Introduction}

Aluminium (Al) alloys are the second most used metallic structural material behind steel. However, $\mathrm{Al}$ alloys have certain advantages over steel where high specific strength, ductility and corrosion resistance are required [1]. Among all lightweight structural material, Al alloys are most promising for automotive and aerospace application from the perspective of high volume manufacturing and lower cost.

Despite their good specific strength, the absolute strength of $\mathrm{Al}$ alloys is generally poor in as-cast condition and requires further strengthening. Cast microstructure of Al alloys also suffers from anisotropic columnar grain structure and uneven distribution of brittle eutectics. Microstructure control and refinement during solidification is necessary not only to improve performance, but also to improve further thermomechanical processability. Three different approaches to refining microstructure have been explored during solidification: (1) addition of chemical inoculants such as $\mathrm{TiB}_{2}$; (2) application of external physical fields such as ultrasonic or electromagnetic force; (3) controlling solidification parameters such as cooling rate and/or pouring temperature [2]. Amongst all these methods, grain refining in wrought aluminium alloys through chemical inoculation has become the standard industrial practice due to its simplicity. Most commonly, Al-5Ti-1B master alloy (containing $\mathrm{TiB}_{2}$ particles) is added at a level of $1 \mathrm{~g}$ per $\mathrm{kg}$ of metal during casting of wrought $\mathrm{Al}$ alloys [3]. However, this grain refiner is mostly ineffective in cast $\mathrm{Al}-\mathrm{Si}$ alloys [4-6]. Eutectic Si modification is commonly achieved by adding $\mathrm{Sr}$ (up to $300 \mathrm{ppm}$ ) [7] or $\mathrm{Na}$ (up to $100 \mathrm{ppm}$ ) [8] promoting a transition from coarse flake to fine fibrous morphology leading to improved ductility. These eutectic modifiers, however, have been linked to 
increase porosity, hot tearing and poor surface quality in castings [7].

The main advantage of physically induced grain refinement over chemical means (inoculation or eutectic modification) comes from their universal applicability rather than being alloy specific. In the last 30 years, significant amount of research has been conducted exploring physical methods such as high-intensity shear [9, 10], lowfrequency mechanical mould vibration [11], electromagnetic stirring [12] or ultrasonic irradiation [13] with varying degrees of success. Amongst them, application of ultrasound has shown most promising grain refinement potential for both cast and wrought Al alloys. Microstructure refining under ultrasound irradiation is still not well understood, especially the mechanism of grain refinement has been debated between dendrite fragmentation and enhanced nucleation. On the other hand, the effect on eutectic morphology has been debated between possible refinement and coarsening.

In this paper, we present experimental evidence on the microstructure modification potential of ultrasound in different $\mathrm{Al}$ alloys covering grain refinement, eutectic modification, effect of solute and comparison against established chemical refinement and suggest likely mechanism behind the microstructure modification.

\section{Experimental Procedure}

Five alloys were selected for the experiments; (1) commercially purity $\mathrm{Al}(\mathrm{CP}-\mathrm{Al}),(2) \mathrm{Al}-5 \mathrm{Cu}$ (all compositions expressed in wt\%), (3) $\mathrm{Al}-10 \mathrm{Cu}$, (4) $\mathrm{Al}-33 \mathrm{Cu}$ and (5) $\mathrm{Al}-$ $11 \mathrm{Si}$ (Al-10.8Si-0.3Fe-0.3Mn). The alloys were melted and homogenised in an electric resistance furnace and taken out in preheated crucibles for ultrasonication. Ultrasound (at $20 \mathrm{kHz}$ ) was transmitted to the solidifying melts from $750{ }^{\circ} \mathrm{C}$ for $\sim 420 \mathrm{~s}$ till near the end of solidification ( $\sim 545-565^{\circ} \mathrm{C}$ melt temperature) through a $25 \mathrm{~mm}$-diameter $\mathrm{Ti}-6 \mathrm{Al}-4 \mathrm{~V}$ radiator introduced below the surface of the melt. The radiator was preheated ( $\sim 400{ }^{\circ} \mathrm{C}$ ) by ultrasonicating a batch of discarded melt first to avoid any chill effect. A thermocouple, connected to a multichannel data logger, was placed below the submerged radiator, and cooling curves were recorded during solidification. Identical experiments were conducted for comparison without ultrasonication for all alloys and with chemical inoculation (using $\mathrm{Al}-5 \mathrm{Ti}-1 \mathrm{~B}$ ) in $\mathrm{CP}-\mathrm{Al}$. Solidified ingots (height $65-70 \mathrm{~mm}$, diameter $50 \mathrm{~mm}$ ) were sectioned along the central vertical plane and ground and polished using standard metallographic techniques. Al-Si samples were unetched, while $\mathrm{Al}-\mathrm{Cu}$ samples were anodized using Barker's reagent $\left(7 \mathrm{ml} 48 \% \mathrm{HBF}_{4}\right.$ in $200 \mathrm{ml}$ distilled water) at $20 \mathrm{~V} \mathrm{DC}$ for $70 \mathrm{~s}$ using a stainless-steel cathode for microstructural analysis using a Zeiss Axioscope microscope. Grain size was measured using linear intercept method over a range of micrographs and considering over 250 grains for each sample.

\section{Results}

\subsection{Grain Refinement in $\mathrm{CP}-\mathrm{Al}$}

Microstructures of $\mathrm{CP}-\mathrm{Al}$ solidified under identical cooling conditions are presented in Fig. 1 from unrefined, chemically inoculated and ultrasonicated samples. In the absence of chemical or physical treatment, fully grown coarse columnar dendrites of few mm length solidifies (Fig. 1a). Considerably finer and equiaxed $\alpha-\mathrm{Al}$ grains can be observed in the Al-5Ti-1B-inoculated samples in Fig. 1b illustrating the effectiveness of chemical refinement. Figure 1c shows the microstructure formed $5 \mathrm{~mm}$ below the radiator in the ultrasonicated ingot. The observed grains are much smaller and more rounded compared with the chemically inoculated ingot. A progressive increase in grain size can be observed with distance from the radiator. However, the grain structure remains equiaxed and the average grain size remains finer than the inoculated sample throughout the ingot. Similar results are observed for the $\mathrm{Al}-\mathrm{Cu}$ alloys, indicating that ultrasonication is more effective in refining grains compared with chemical inoculation in small volume of melt as in the present case. More importantly, the grain refining efficiency near the ultrasound radiator is spectacular. This is primarily the area of active cavitation, highlighting the important role the cavitation plays in grain refinement under ultrasonication. Reduction in cavitation with distance from the radiator leads to reduction in refinement potential though dispersion of nuclei and grains through acoustic streaming effect leads to overall equiaxed microstructure observed in small ingots.

\subsection{Effect of Solute on Grain Refinement}

Figure 2 presents optical micrographs from the top of the ultrasonicated ingots of $\mathrm{Al}-5 \mathrm{Cu}$ (Fig. 2a) and $\mathrm{Al}-10 \mathrm{Cu}$ (Fig. 2b) along with the plotted average grain size from the $\mathrm{CP}-\mathrm{Al}$ and $\mathrm{Al}-\mathrm{Cu}$ ingots (Fig. 2c). It is clear that ultrasonication further refines the grain size in $\mathrm{Al}-\mathrm{Cu}$ alloys compared with $\mathrm{CP}-\mathrm{Al}$ and the refinement effect is enhanced with an increase in solute content (compare Fig. 2a, b). Figure 2c also presents the ingot average grain size from the unrefined ingots, and the grain size drastically decreases with increased $\mathrm{Cu}$ content. This is expected from the constitutional undercooling effect of solute $\mathrm{Cu}$ promoting growth restriction and heterogeneous nucleation 

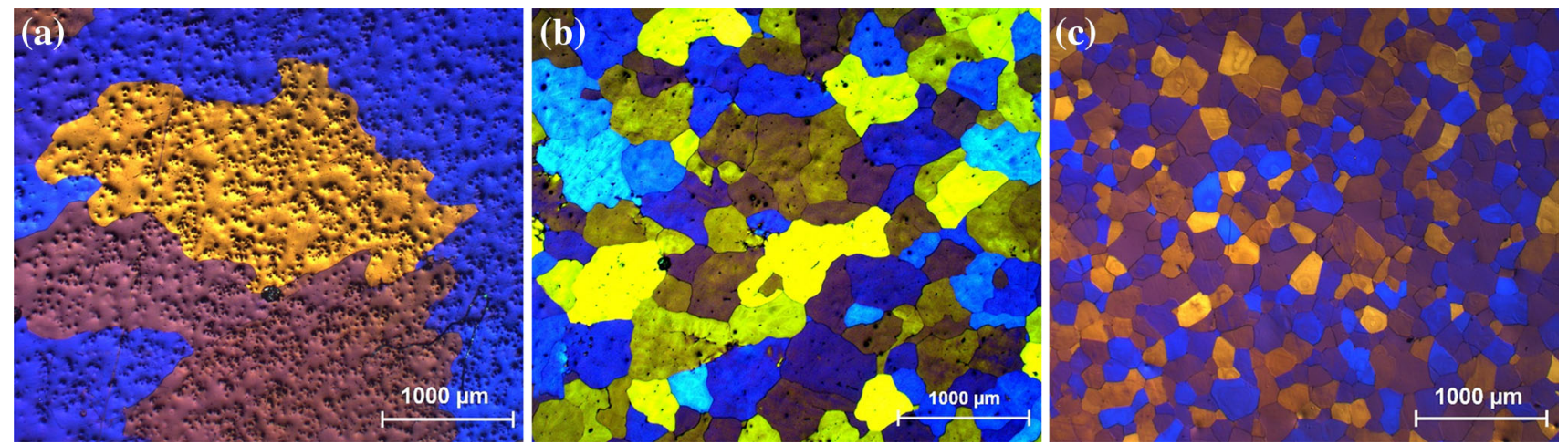

Fig. 1 Optical micrographs from $\mathrm{CP}-\mathrm{Al}$ solidified ingots a without refinement, $\mathbf{b}$ chemically inoculated and $\mathbf{c}$ ultrasonicated

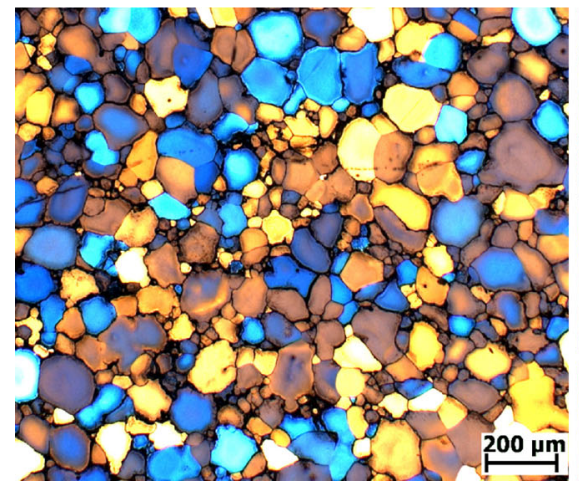

(a)

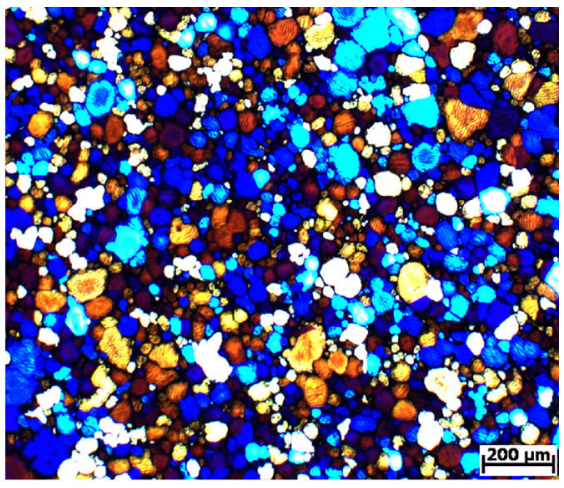

(b)

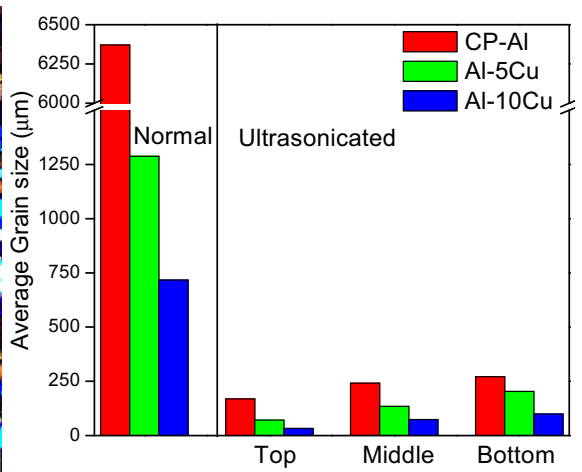

(c)

Fig. 2 Optical micrographs from the top of ultrasonicated ingots of a $\mathrm{Al}-5 \mathrm{Cu}$ and $\mathbf{b} \mathrm{Al}-10 \mathrm{Cu}$. $\mathbf{c}$ The average grain size in unrefined and ultrasonicated $\mathrm{CP}-\mathrm{Al}$ and $\mathrm{Al}-\mathrm{Cu}$ ingots

during conventional solidification. The average grain size from the ultrasonicated ingots is presented from the top (just below the radiator), middle and bottom of the ingots in Fig. $2 c$ and shows dramatic reduction in grain size throughout the ingot. For all three alloys, a progressive increase in grain size is noted with distance from the radiator, as mentioned in the previous section. Noticeably, all regions in the ingot show a direct correlation between grain size and solute content as in the conventionally solidified unrefined ingots. This is also prominent at the top of the ingot, in the area of active cavitation just below the ultrasound radiator, illustrating that strong fluid flow under ultrasonication does not diminish growth restriction effect of solute during solidification. Accordingly, the grain refinement potential of ultrasound could be further enhanced with careful addition of solute.

\subsection{Modification of Eutectic Microstructure}

Eutectic microstructures formed without and under ultrasonication are presented in Fig. 3 from the top of the ingots (immediately below the radiator for ultrasonicated ones). Figure 3a shows typical microstructure observed in the eutectic $\mathrm{Al}-33 \mathrm{Cu}$ alloy ingot solidified without ultrasonication. $\mathrm{Al}-\mathrm{Cu}$ represents a regular eutectic system, and the microstructure consists of eutectic colonies consisting of lamellar $\mathrm{Al}_{2} \mathrm{Cu}$ (dark) and $\alpha$ - $\mathrm{Al}$ (light) phases. The intercolony boundaries are distinguished by coarser lamellar spacing. A completely degenerated microstructure solidified under ultrasonication is shown in Fig. 3b. The lamellar eutectic is predominantly replaced by coarser and rounded $\mathrm{Al}_{2} \mathrm{Cu}$ and $\alpha$-Al particles. There are some isolated lamellar regions observed scattered between the degenerated microstructure with coarser lamellar spacing compared to Fig. 3a. These lamellar regions are presumed to be solidified following the withdrawal of ultrasound (near the end of solidification). Figure $3 \mathrm{c}$, $\mathrm{d}$ shows microstructures from the $\mathrm{Al}-11 \mathrm{Si}$ alloy that represent an irregular eutectic system. In the absence of ultrasonication, long, faceted and randomly oriented eutectic Si needles (dark grey) form in the microstructure (Fig. 3c). The light grey Chinese-scriptshaped phase seen in the microstructure represents $\alpha$ $\mathrm{Al}(\mathrm{Fe}, \mathrm{Mn}) \mathrm{Si}$ intermetallic particles. Microstructure just below the radiator in the ultrasonicated ingot (Fig. 3d) shows that eutectic $\mathrm{Si}$ has solidified mainly as compact polygonal particles (dark grey). There are some very thin 
Fig. 3 Regular eutectic microstructure from the top of $\mathrm{Al}-33 \mathrm{Cu}$ ingots solidified a conventionally and $\mathbf{b}$ under ultrasonication where dark phase represents $\mathrm{Al}_{2} \mathrm{Cu}$ and light phase $\alpha$-Al. Irregular eutectic microstructure from the top of Al-11Si ingots solidified c conventionally and $\mathbf{d}$ under ultrasonication showing morphologies of $\alpha$-Al (light), eutectic Si (dark grey) and $\alpha$ $\mathrm{Al}(\mathrm{Fe}, \mathrm{Mn}) \mathrm{Si}$ intermetallics (light grey)
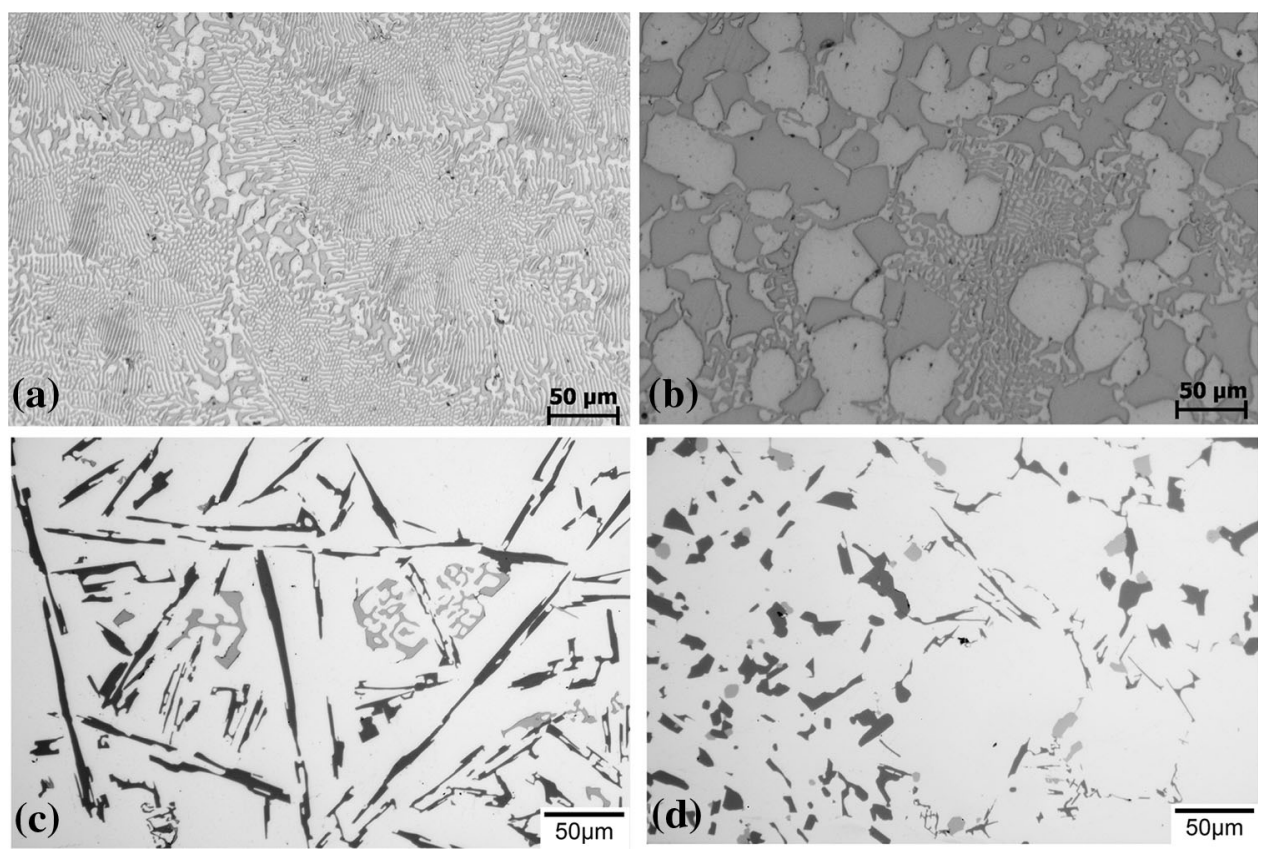

and short Si platelets found uniformly distributed between some $\alpha$-Al (white) grains that are formed after the withdrawal of ultrasonication in the remnant intergranular liquid. $\alpha-\mathrm{Al}(\mathrm{Fe}, \mathrm{Mn}) \mathrm{Si}$ intermetallic phase (light grey) has also transformed from complex Chinese-script morphology to compact polygonal particles. The effect of ultrasound on eutectic morphology can be observed to be drastic in the area of active cavitation spanning around $15 \mathrm{~mm}$ from the radiator. Beyond this, microstructure modification effect diminishes much more rapidly compared with primary phase morphology that shows gradual variation in the morphology and grain size with distance.

\section{Discussion}

\subsection{Origin of Grain Refinement Under Ultrasonication}

Figures 1 and 2 demonstrate that ultrasonication significantly refines $\alpha$-Al grains as compared to unrefined or even chemically refined ingots. While the refinement is strongest near the radiator, the whole ingot microstructure is considerably refined. The major effects of ultrasonication in alloy melts are contributed by cavitation (instantaneous formation and collapse of gas-filled bubbles) and acoustic streaming (long-range fluid flow generated through attenuation of ultrasound) that account for grain refinement [13]. Grain refinement effect is generated mainly under cavitation due to the shockwave (1000 atm) and strong microjet $(100 \mathrm{~m} / \mathrm{s})$ formation. Acoustic streaming primarily aids refinement by distributing cavitation-generated nuclei in the bulk melt. Origin of refinement under cavitation is debated between (1) mechanical fragmentation of dendrite arms [13] and (2) cavitation-enhanced heterogeneous nucleation [14]. Cooling curves recorded during the solidification of $\mathrm{Al}-10 \mathrm{Cu}$ and $\mathrm{Al}-11 \mathrm{Si}$ alloys are presented in Fig. 4a, b, respectively. There is noticeable reduction in the nucleation undercooling (increase in nucleation temperature) for primary $\alpha$-Al under ultrasonication in both alloys providing clear evidence of enhanced nucleation. The efficiency of nucleation appears to be similar to chemical refinement with identical reduction in nucleation undercooling recorded (Fig. 4a). However, no recalescence is recorded under ultrasonication as opposed to chemical inoculation. This will prolong nucleation and explains the better refinement observed under ultrasonication compared with chemical inoculation. It has been suggested that pressure-pulse-induced increase in the equilibrium freezing point may activate indigenous nucleating substrates in the melt and efficient dissipation of latent heat allows them to act as effective nucleating agents under cavitation leading to copious nucleation under ultrasonication [15].

\subsection{Origin of Eutectic Modification Under Ultrasonication}

Figure 3 clearly demonstrates that eutectic microstructure is noticeably altered in the cavitation zone (near the ultrasonic radiator). This alteration in morphology is observed for both regular and irregular eutectics. Unlike in primary grain refinement, eutectic modification does not appear to result from any enhanced nucleation. Eutectic in commercial Al-Si alloys forms with high nucleation rate at 

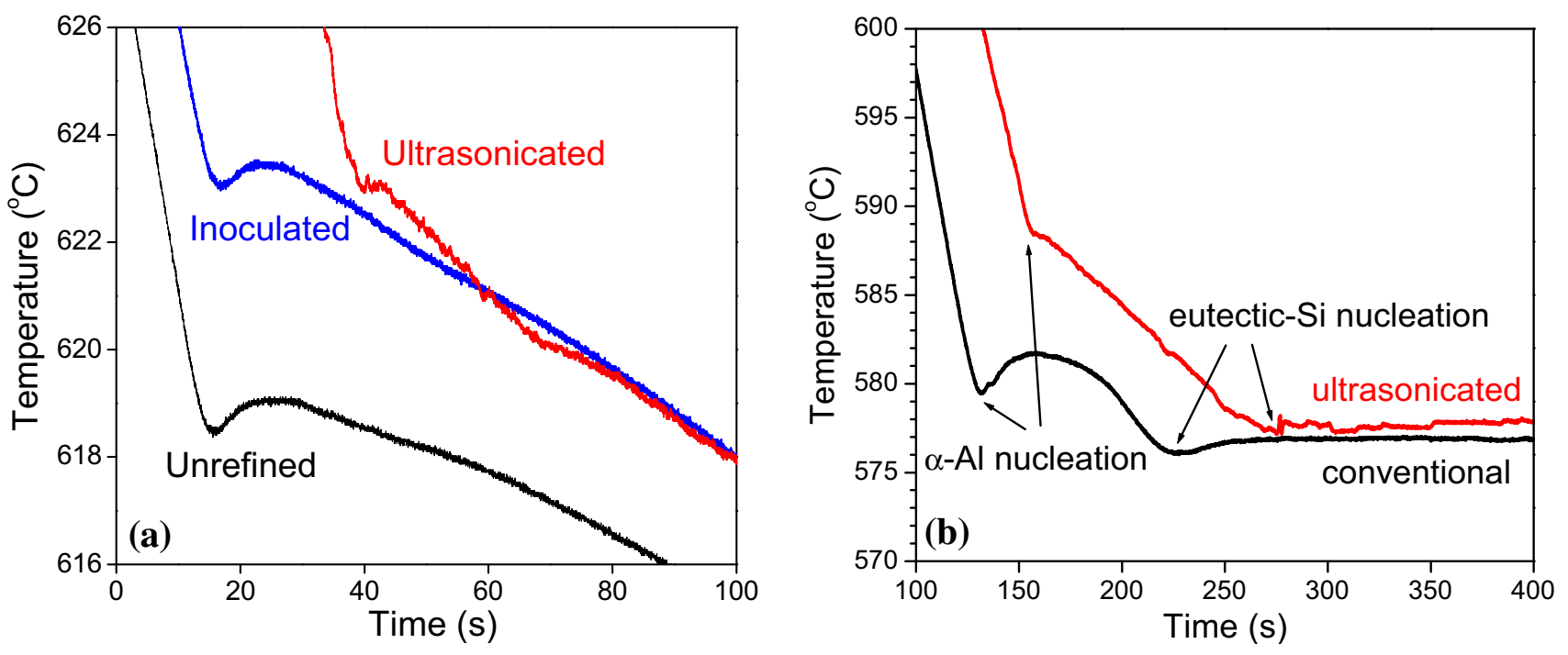

Fig. 4 Cooling curves recorded during the solidification of $\mathbf{a} \mathrm{Al}-10 \mathrm{Cu}$ [15] and $\mathbf{b} \mathrm{Al}-11 \mathrm{Si}$ [4] ingots

low undercooling [16]. Therefore, contribution to eutectic nucleation by any AIP particle dislodged under cavitation is probably negligible. Cooling curves presented for the Al-11Si alloy (Fig. 4b) show nominal change in the eutectic nucleation undercooling under ultrasonication (unlike for $\alpha$-Al nucleation), indicating negligible difference in nucleation behaviour. Modification of eutectic morphology appears to originate from coarsening and spheroidisation effects from solute homogenisation at the eutectic growth front under extremely strong convection in the region of cavitation $[4,5]$. It should be noted that the diffusion boundary layer formed ahead of the eutectic growth front persists only over a very short distance. Coarsening and/or decoupling of the lamellar growth requires altering this extremely thin diffusion layer. This is possible under the shockwave created through cavitation. Accordingly, degeneration and spheroidisation of eutectic are only prominent over a short distance (about $15 \mathrm{~mm}$ ) around the radiator. Although fluid flow persists in the bulk melt from acoustic streaming effects, it is not strong enough to alter the thin eutectic diffusion layer and the effect of ultrasonication on the eutectic morphology rapidly diminishes beyond $15 \mathrm{~mm}$ from the radiator. This contrasts with grain refinement where acoustic streaming distributes nuclei in the bulk melt leading to overall grain refinement in the entire ingots. The thin short $\mathrm{Si}$ platelets observed between $\alpha$-Al grains in Fig. $4 \mathrm{~d}$ are not directly influenced by ultrasonication as they are formed in the last eutectic to freeze after the ultrasonic withdrawal. These intergranular liquid pockets are small with large contact area with the existing solid resulting in high cooling rate and limited growth for the $\mathrm{Si}$ plates, thereby influencing the morphology.

\section{Concluding Remark}

- Ultrasonication of melt during solidification till the semi-solid stage has shown significant grain refinement in commercial purity $\mathrm{Al}$ as well as in various $\mathrm{Al}-\mathrm{Cu}$ alloys. The extent of refinement is superior to chemical inoculation in a small volume of melt.

- Eutectic microstructure in both regular and irregular eutectic shows drastic decoupling of lamellar structures and coarsening to compact polygonal microstructures instead of lamellar or plate-type morphology in the area of cavitation within $15 \mathrm{~mm}$ from the radiator.

- Grain refinement under ultrasonication originates from enhanced nucleation showing a noticeable reduction in the nucleation undercooling presumably from pressure pulse effect on the freezing point. On the other hand, modification of eutectic microstructure is caused by coarsening and spheroidisation under the strong fluid flow from cavitation.

Acknowledgement Dr Hiren Kotadia thanks the support of WMGHigh Value Manufacturing Catapult.

Open Access This article is distributed under the terms of the Creative Commons Attribution 4.0 International License ( http://creativecommons.org/licenses/by/4.0/), which permits unrestricted use, distribution, and reproduction in any medium, provided you give appropriate credit to the original author(s) and the source, provide a link to the Creative Commons license, and indicate if changes were made. 


\section{References}

1. J. Davis, ASM Specialty Handbook: Aluminum and Aluminum Alloys. ASM International (1993).

2. Murty B S, Kori S A, Chakraborty M, Int Mater Rev 47 (2002) 3.

3. Greer A L, Cooper P S, Meredith M W, Schneider W, Schumacher P, Spittle J A, Tronche A, Adv Eng Mater 5 (2003) 81.

4. Das A, Kotadia H R, Mater Chem Phys 125 (2011) 853.

5. Kotadia H R, Das A, J Alloys Compd 620 (2015) 1.

6. Nowak M, Bolzoni L, Hari Babu N, Mater Des 66 (2015) 366

7. Campbell J, Tiryakioğlu M, Mater Sci Technol 26 (2010) 262.

8. Flood S C, Hunt J D, Metal Sci 15 (1981) 287.
9. Kotadia H R, Hari Babu N, Zhang H, Arumuganathar S, Fan Z, Metall Mater Trans A 42 (2011) 1117.

10. Kotadia H R, Doernberg E, Patel J B, Fan Z, Schmid-Fetzer R, Metall Mater Trans A 40 (2009) 2202.

11. Kocatepe K, Burdett C F, J Mater Sci 35 (2000) 3327.

12. Vives C, Metall Trans B 20 (1989) 623.

13. Eskin G I, Eskin D G, Ultrasonic Treatment of Light Alloys Metals, 2nd Ed, CRS Press, BocaRaton (2014).

14. Hunt J D, Jackson K A, J Appl Phys 37 (1966) 254.

15. Kotadia H R, Qian M, Eskin D G, Das A, Mater Des 132 (2017) 266.

16. McDonald S D, Nogita K, Dahle A K, Acta Mater 52 (2004) 4273. 